scuk 7 (Financial Planning for Multinational Opera. tions) gaat in op projectevaluatie-technieken ten be hoeve van buitenlandse operaties, de internationale kapitaalmarkten en het vreemde valuta manage ment. Afhankelijk van de gehanteerde valuta omre. kening wordt het vreemde valuta management geconfronteerd met een economische-, een omreke nings en een politiek risico.

In hoofdstuk 8 (Management Information Systems and Control) wordt systematisch ingegaan op de informatiesystemen, interne controle en management audits bij MNO'en. De diverse nationale belastingstelsels, belastingverdragen en de fiscale planning voor internationaal vertakte ondernemin. gen worden beknopt weergegeven in hoofdstuk 9 (Multinational Taxation and Transfer Pricing); te. vens wordt uitgebreid ( 9 bladzijden) ingegaan op de problemen van interne verrekenprijzen in een internationale ondernemingsstructuur.

Het laatste hoofdstuk (Current Issues and Devel opments) is algemeen van aard. Aan de orde komen de controversiële aspecten van het instituut MNO, de verslaggevingsvoorschriften van de OECD en de VN, de accounting ten behoeve van de sociale ver. antwoordelijkheid van een MNO en de accounting in economisch en sociaal minder-ontwikkelde lan den.

Samenvattend kan gesteld worden dat Choi en Mueller er in geslaagd zijn een zich snel uitbreidend en gecompliceerd vakgebied in overzichtelijke vorm te presenteren. Aan de doelstelling met betrekking tot het voorzien in een adequaat leerboek is dan ook in ruime mate voldaan. Voomamelijk ten gevolge van de dikwijls beknopte stijl en de uitgebreide refe. renties aan het eind van ieder hoofdstuk, zal de lezer dit werk kunnen hanteren als een eerste oriëntatie in de internationale of multinationale accountancy. Voor de meer academisch gerichte gebruiker is de tekst op zich niet toereikend, echter de discussie.vra gen, het casus-materiaal en de door de auteurs ge suggereerde nieuwe onderzoeks projecten zijn bij zonder waardevol. Zoals bij vele Amerikaanse boe. ken is de aandacht die aan de controleleer (auditing) wordt besteed ondergeschikt aan de financiële ver slaggevings-aspecten; desondanks wordt in voldoen de mate verwezen naar literatuur over controleleer in een internationaal verband.

"An Introduction to Multinational Accounting" is voor een ieder, die geinteresseerd is in dit relatief nieuwe vakgebied, zeer aanbevelenswaardig.

\title{
BINNENGEKOMEN BOEKEN
}

Accounting, accountancy; werkterrein van accoun. tants?

Prof. Drs. Sj. Muller

Uitgeverij H. E. Stenfert Kroese B.V. te Leiden

Prijs $f 14,50$

Internationale economische betrekkingen in hoofd. lijnen

J. C. P. A. van Esch

Uitgeverij H. E. Stenfert Kroese B.V. te Leiden

Prijs $f 32,50$

Zesde richdlijn en Nederlandse omzetbelasting

Mr. D. B. Bijl en J. B. van der Zanden

Uitgeverij Kluwer B.V. te Deventer

Prijs $f 27,50$

Financiële analyse van ondernemingen

Theorie en toepassing op het Koninklijk Besluit m.b.t de jaarrekening

Dr. H. Ooghe

Uitgeverij H. E. Stenfert Kroese B.V. te Leiden

Prijs $f$ 75,-
Grondslagen van de administratieve organisatie (12e druk)

J. van Nimwegen en E. O. J. Jans

Uitgeverij Samsom B.V. te Alphen aan den Rijn

Prijs $f$ 49,80

WIR, een praktische toelichting

Drs. M. C. van der Harst en Drs. J. A. M. Klaver

Uitgeverij Kluwer B.V. te Deventer

Prijs $f$ 25-

Financial Ratios. Analysis and Prediction

M. Tamari

Uitgeverij Paul Elek te Londen

Prijs $£ 9.95$

Fiscale aspecten van goederen- en dienstenverkeer tussen gelieerde maatschappijen (Nr. 2 in de serie Fiscale en juridische documentatie voor internatio. naal zakendoen)

Mr. J. de Kater en Dr. M. R. Reuvers

Met discussiebijdragen van Mr. F. van Brunschot,

Dr. N. Nobel en Dr. K. Rijks

Uitgeverij Kluwer B.V. te Deventer

Prijs $f$ 21,- 
Financieel Memo 1978

Uitgeverij Kluwer B.V. te Deventer

Prijs $f$ 14,-

Financiering en belegging. Stand van zaken anno 1978

Onder redactie van M. J. L. Jonkhart/J. W. R. Schuit/J. Spronk

Uitgeverij H. E. Stenfert Kroese B.V. te Leiden Prijs $f$ 35,-

Wir en Sir. Verslag van een seminar over dit onder werp, gehouden op 8 juni 1978 te Amsterdam Prof. Dr. J. H. Christiaanse (voorzitter), Drs. G. H. B. Verberg, Drs. H. A. Kogels, Mr. K. Sneep en Prof. Drs. J. W. Schoonderbeek

Uitgeverij Kluwer B.V. te Deventer

Prijs $f$ 24,50
Zeven intrestrafels (2e, herziene en uitgebreide druk) Drs. J. J. M. Michels en Drs. A. J. van Reeken Uitgeverij H. E. Stenfert Kroese B.V. te Leiden Prijs $f$ 29,50

De toekomst van ons werk Een bundel opstellen over het evenwicht tussen vrijheid en gelijkheid Jaap Boersma/Kenneth E. Boulding/William R. Dill/Jef A. P. van Hoof/Branko Horvat/John Hughes/Bertrand de Jouvenel/Sven Lindqvist/Jan Tinbergen

Geredigeerd en ingeleid door Geert Hofstede Uitgeverij H. E. Stenfert Kroese B.V. te Leiden Prijs $f$ 25,-

Wet investeringsrekening. Commentaar op Wir en Sir.

Mr. H. M. N. Schonis en Drs. J. Renes Uitgeverij Gouda Quint B.V. te Arnhem Prijs f 49,50

In dit nummer schreven:

PROF. MR. C. A. BOUKEMA, geboren 1933. Studeerde rechten aan de Vrije Universiteit te Amsterdam, promoveerde te Leiden op een proefschrift getiteld „Ci. vielrechtelijke samenloop", was werkzaam op de juridische afdeling van de Hoog. ovens en is sedert 1967 hoogleraar in de rechtswetenschap aan de economische faculteit van de Universiteit van Amsterdam.

DRS. D. M. G. DE CHAMPEAUX DE LABOULAYE, geboren 1941. Doctoraal examen zuivere wiskunde aan de Universiteit van Amsterdam, 1967. Sinds 1969 verbonden aan de Economische Faculteit van Amsterdam. Diverse publicaties voornamelijk op het gebied van de Kunstmatige Intelligentie.

DRS. C. LIPPENS, geboren 1950. Doctoraalexamen bedrijfseconomie aan de Erasmus Universiteit te Rotterdam, 1976. Sedert anderhalf jaar werkzaam als secretaris van de Stichting Opleidings en Ontwikkelingsfonds voor de Bouwnijverheid. Deze Stichting financiert grotendeels de opleidings- en researchinstituten in de bouwnijverheid.

J. F. VAN DIJK, geboren 1921. Accountantsdiploma NIvA 1956. Was gedurende circa 38 jaar werkzaam in verschillende functies bij de lagere overheid, alsmede in de gemeentelijke accountancy, waarvan 14 jaar als directielid van het Centraal Bureau voor Verificatie en Financiële Adviezen. Accountantskantoor van de Ver. eniging van Nederlandse Gemeenten. Sedert 1-1.1978 directeur Limperg Instituut, interuniversitair instituut voor accountancy. Oud-bestuurslid NIVRA en NOVI. Lid CTB en secretaris COPA van het NIVRA. 